\title{
Correlation between neurological features, nutritional status and metabolic changes in patients with Ataxia-telangiectasia
}

\section{Talita Lemos Neves Barreto ( $\nabla$ talita.lemos@unifesp.br)}

UNIFESP: Universidade Federal de Sao Paulo https://orcid.org/0000-0001-5440-4615

Ivana Raslan

UNIFESP: Universidade Federal de Sao Paulo

Karina Trajano

UNIFESP: Universidade Federal de Sao Paulo

Fernanda Maggi

UNIFESP: Universidade Federal de Sao Paulo

José Luiz Pedroso

UNIFESP: Universidade Federal de Sao Paulo

Orlando Barsottini

UNIFESP: Universidade Federal de Sao Paulo

\section{Fernando Luiz Fonseca}

Faculdade de Medicina do ABC

\section{Ariel Ferreira}

Faculdade de Medicina do ABC

\section{Carolina Aranda}

UNIFESP: Universidade Federal de Sao Paulo

\section{Roseli Sarni}

Faculdade de Medicina do ABC

\section{Research}

Keywords: Ataxia-telangiectasia, Assessment and Rating of Ataxia, International Cooperative Ataxia Rating Scale, Liver disease, Insulin resistance, Nutritional status

Posted Date: January 29th, 2021

DOl: https://doi.org/10.21203/rs.3.rs-154838/v1

License: (c) (i) This work is licensed under a Creative Commons Attribution 4.0 International License. Read Full License 


\section{Abstract \\ Background}

Ataxia-telangiectasia (AT) is an autosomal recessive neurodegenerative disorder caused by variants of ATM (ataxia telangiectasia mutated) gene. There is no specific treatment, but clinical management has advanced resulting in longer patient survival. However, these patients develop metabolic changes over time. We aimed to assess the correlation between neurological features, nutritional status and metabolic changes in AT patients.

\section{Results}

Significant correlations were found between the scores on the International Cooperative Ataxia Rating Scale (ICARS) and age ( $r=0.748 ; p<0.001)$, gamma glutamyl transferase (GGT) $(r=0.743 ; p<0.001)$, insulin levels $(r=0.520 ; p=0.016)$ and the Homeostasis Model Assessment for Insulin Resistance (HOMA-IR) index ( $r=0.585 ; p=0.005)$ as well as the scores on the Assessment and Rating of Ataxia (SARA) and age $(r=0.704 ; p<0.001)$, GGT $(r=0.701 ; p<0.001)$, insulin levels $(r=0.706 ; p<0.001)$ and HOMA-IR index $(r=0.764 ; p<0.001)$.

\section{Conclusions}

The relevant correlation between severity of ataxia and disease progression with metabolic changes such as liver function impairment and insulin resistance reinforce the importance to monitoring metabolic changes and evaluate nutritional status in these patients.

\section{Background}

Ataxia-telangiectasia (AT) is a rare autosomal recessive neurodegenerative disorder that usually starts in early childhood [1,2]. AT is caused by variants of ATM (ataxia telangiectasia mutated) gene encoded on chromosome 11q22-23, which causes failure of the ATM protein, a serine/threonine kinase that participates in cellular processes for maintaining genomic stability such as identification of errors, DNA repair and cell-cycle control [3].

AT is characterized by complex phenotypes comprising progressive cerebellar ataxia, ocular and cutaneous telangiectasia, oculomotor apraxia, immunodeficiency at varying degrees, increased predisposition for cancers, cellular radiosensitivity and malnutrition with loss of lean body mass [3-6]. The extended disease phenotype also includes growth retardation, premature aging, insulin resistance, hepatic impairment, type 2 diabetes, manifestations of mitochondrial dysfunction, inadequate responses to oxidative stress and increased cardiovascular risk [7]. 
Most typical symptoms of AT include early onset cerebellar ataxia and dilated capillaries at the angles of the eyes and on the skin (telangiectasia). In general, ataxia is the first major clinical sign, and usually starts around 5-year-old [8,9]. High serum levels of alpha-fetoprotein (AFP) is a relevant biomarker to confirm the diagnosis of AT [10].

To date, there is no specific treatment for AT. Advances in clinical management with multidisciplinary approaches have resulted in increased patient survival. However, these patients may develop metabolic changes and comorbidities that affect the disease course and their quality of life.

Studies conducted by our group have shown that age advanced is associated with insulin resistance and hepatic impairment in patients with AT [11,12]. With disease progression, AT patients usually present nutritional status impairment [13-18]. Thus, this study aimed to assess the correlation between neurological features, nutritional status and metabolic changes in patients with AT.

\section{Methods}

\section{Patients}

This is a cross-sectional study with prospective data from patients with AT $(n=25)$ who met the diagnostic clinical criteria of the European Society for Immunodeficiencies (ESID) [19]. The sample was comprised both male and female patients aged from 5 to 31 years who were followed up at the Division of Allergy, Clinical Immunology, Rheumatology and Neurology outpatient clinic of Universidade Federal de São Paulo (UNIFESP) Department of Pediatrics in São Paulo, Brazil.

The study was approved by UNIFESP Research Ethics Committee (nr. 0081/2018). All patients or their caregivers signed an informed consent to be enrolled in this study.

\section{Anthropometric assessment}

Anthropometric measurements included weight, height and skinfolds (tricipital, bicipital, subscapular and suprailiac) $[20,21]$. Those who were unable to stand were weighed on a digital wheelchair scale (Micheletti® electronic weighing platform for up to $500 \mathrm{~kg}$ ). Recumbent height measurements were taken in supine position on a flat, firm surface by using a non-extensible tape (in millimeters).

For nutritional status classification, body mass index (BMI)-for-age z-scores and height-for-age z-scores for children and adolescents were calculated. Adults were classified according to BMI $[20,22]$. The sum of skinfold measures was used to estimate body composition [23-26].

The stage of pubertal development was self-assessed using the Tanner rating scale (Marshall \& Tanner) [27].

\section{Biochemical markers}


Biochemical markers and metabolic tests evaluated included: alanine aminotransferase (ALT) (kinetic ultraviolet assay); aspartate aminotransferase (AST) (kinetic ultraviolet assay); gamma glutamyl transferase (GGT) (kinetic enzyme assay); fasting insulin and glucose (oxidase/peroxidase enzyme assay); and AFP (electrochemiluminescence assay). The Homeostasis Model Assessment for Insulin Resistance (HOMA-IR) index was used to estimate peripheral insulin resistance.

\section{Neurological assessment}

Two rating scales, The International Cooperative Ataxia Rating Scale (ICARS) and the Scale for the Assessment and Rating of Ataxia (SARA), were applied by two skilled physical therapists to evaluate ataxia severity in all patients. General neurological examination and a routine brain magnetic resonance imaging (MRI) were also evaluated.

The ICARS is culturally adapted and validated for Brazil. This 19-item scale is divided into 4 subscales (scores 0-100): posture and gait disturbances (items 1 to 7; scores $0-34$ ); limb ataxia (items 8 to 14; scores 0-52); dysarthria (items 15 and 16; scores 0-8); and oculomotor disorders (items 17 to 19; scores $0-6$ ). ICARS cutoff points were: 1 to 30 , mild ataxia; 31 to 60 , moderate ataxia; and $>60$, severe ataxia [28].

The second scale used was SARA, which has been translated into Brazilian Portuguese and validated for Brazil. It is an 8-item scale for a total score of 40: gait ( $0-8$ points); stance ( $0-6$ points); sitting ( $0-4$ points); speech disturbance ( $0-6$ points); finger chase ( $0-4$ points); nose-finger test ( $0-4$ points); fast alternating hand movements ( $0-4$ points); and heel-shin slide (0-4) [29]. Ataxia was rated as mild (scores $<22$, ability to walk with or without walking aids); moderate (scores 15-33, frequent use of wheelchair and ability to take a few steps with walking aid and use of upper limbs); or severe (scores $>30$, bound to wheelchair) [30].

\section{Statistical analysis}

The data were entered into an Excel spreadsheet (Office Microsoft ${ }^{\circledR}$ ) and analyzed using SPSS Statistics 19.0 (IBM $\left.{ }^{\circledR}\right)$. Categorical variables were presented as absolute and percentage values. Continuous variables were analyzed for normality using the Shapiro-Wilk test. For comparisons between the two age groups evaluated, independent t-Student test was used to compare parametric variables (means and standard deviations) and the two-tailed Mann-Whitney $U$ test was used to compare non-parametric variables (medians, minimum and maximum). Spearman's correlation coefficient was used to assess correlations. The level of statistical significance was set at $5 \%(p<0.05)$.

\section{Results}

From the sample of 25 patients with AT evaluated, 16/25 (64\%) were male, the median age of 13 (5-31) years. The median age at diagnosis was $4.0(1-16)$ years. Family history of consanguinity was documented in 13/25 (52\%) patients. Cerebellar atrophy was detected in 15/18 (83.3\%) patients who underwent brain MRI. 
Regarding nutritional status, 8/25 (32\%) were malnourished; only 1/25 (4\%) was overweight; and 8/19 (42\%) showed short stature for age. The assessment of the body fat composition revealed low percentage of body fat in $4 / 24(16.6 \%)$ and high percentage of body fat in $7 / 24$ (29.1\%). Low lean body mass was seen in $13 / 24(54.1 \%)$ patients.

As for neurological manifestations, mean age of symptom onset was $10( \pm 4.3)$ months. Cerebellar ataxia was the most common sign seen in 15/25 (60\%) patients. Mean age of loss of independent gait was 8 ( \pm 2.0) years; $13 / 25(52 \%)$ patients had the ability of walking with aid and $5 / 25(20 \%)$ showed inability to walk.

ICARS scores indicated moderate ataxia in 13/25 (52\%) patients and severe in 9/25 (36\%). SARA scores indicated moderate ataxia in 9/25 (36\%) patients and severe in 9/25 (36\%). Table 1 shows the characteristics of patients with A-T.

Table 1 Characteristics of patients with AT

Our sample was classified into two age groups ( $\leq 12$ years; $>12$ years) to compare biochemical markers. Significant differences were found between the age groups for ALT $(p=0.017)$, GGT $(p<0.001)$ and AFP $(p=0.006)$. Table 2 shows the comparison of biochemical markers between the two age groups. Figure 1 shows the comparison of GGT, ALT and AFP results between these groups.

Table 2 Comparison of biochemical markers in patients with AT by age groups

Figure 1 Boxplot of GGT (a); boxplot of ALT (b); and boxplot of AFP (c) for the age groups $\leq 12$ years $(n=$ $10)$ and $>12$ years $(n=15)$

The median score on ICARS was 57 (7-87). Significant direct correlations were found between ICARS scores and age $(r=0.748 ; p<0.001)$, GGT $(r=0.743 ; p<0.001)$, insulin $(r=0.520 ; p=0.016)$, and HOMA-IR index $(r=0.585 ; p=0.005)$. There was a trend towards indirect significance of the correlation between these scores and height-for-age $z$-scores $(r=-0.427 ; p=0.068)$.

The median score on SARA was 20.5 (3-32). Significant direct correlations were seen between SARA scores and age ( $r$ o $=0.704 ; p<0.001)$, GGT $(r=0.701 ; p<0.001)$, insulin $(r=0.706 ; p<0.001)$, and HOMAIR index $(r=0.764 ; p<0.001)$. There was an indirect correlation of these scores with height-for-age $z-$ scores $(r=-0.462 ; p=0.046)$.

A strong correlation was found between the two rating scales $(r=0.900 ; p<0.001)$. Figure 2 shows the correlation between ICARS and SARA scores and age.

Figure 2 (a) Scatterplot of SARA and ICARS scores; (b) Scatterplot of ICARS scores versus age; and (c) Scatterplot of SARA scores versus age (c)

\section{Discussion}


Our study found a marked correlation between severity of ataxia and nutritional and metabolic changes in patients with AT. Statistical analysis showed significant difference when ICARS and SARA rating scales were compared with, GGT, fasting insulin and HOMA-IR index. It is noteworthy that both ICARS and SARA were able to detect those patients with severe ataxia, which evidences their rating agreement especially for the most severe form of the disease. This study shows correlations between worsening of ataxia manifestations with age and metabolic changes including impairment of liver function and insulin resistance in patients with AT.

Patients with AT may develop diabetes as a complication in late adolescence and they usually present with high blood glucose levels without glycosuria or ketosis and high levels of insulin in response to glucose administration [31]. Two studies with patients with AT undergoing the 2-hour oral glucose tolerance test reported increased postprandial blood glucose levels and insulin resistance [11,32].

Some previous data have shown that insulin acts on all types of cells in the central nervous system (CNS) including neurons, astrocytes, oligodendrocytes, ependymal cells, brain endothelial cells and microglia. In fact, all cell types in the CNS express insulin receptors, which suggests their ability to respond to insulin. On a functional basis, insulin resistance can affect brain function and result in cognitive and neurodegenerative changes which could explain our findings [33].

Chronic liver dysfunction can lead to the accumulation of toxic metabolites in the brain and cause neuroinflammation by increasing pro-inflammatory cytokines and oxidative and nitrosative stress (nitric oxide) [34]. A recent retrospective cohort study of 67 patients with AT aged 1 to 38 years found a significant correlation between Klockgether ataxia score (KAS) and GGT and age, which corroborates our findings [35]. Our results suggest that liver dysfunction in patients with AT may indicate greater disease severity and more severe neurological symptoms. Therefore, it is recommended to evaluate liver function (especially GGT) as part of routine evaluations in patients with AT as GGT seems to have a more significant relationship with neurological decline.

A comparison of biochemical markers between the age groups ( $\leq 12$ years and $>12$ years) in our study revealed that liver enzyme, ALT, GGT and AFP, were significantly higher among older patients. Elevated AFP levels are characteristic of AT and they apparently increase with age [10].

Regarding liver enzymes, a study carried out by our group found that levels of ALT and AST were more significantly altered from adolescence in patients with AT. Those patients who developed liver dysfunction tended to be older and had higher sum of insulin levels than those with hepatic steatosis only or no liver dysfunction [11]. Donath et al. reported steady elevation of ALT and GGT levels from the age of 12 in AT, which is in line with our results [35]. Weiss et al. reported elevated liver enzymes in young AT patients (age $9.97 \pm 5.09$ years) associated with dyslipidemia, but not with age [36].

Most patients with AT, particularly those with the classic form of the disease, have malnutrition and stunted growth even with adequate energy intake. It is thus believed to be a multifactorial condition associated with the severity of neurological impairment [8]. Although we did not find a significant 
correlation between ataxia scores and BMI, all eight patients with malnutrition, regardless of their age, showed moderate or severe ataxia. Moreover, stunted growth may also be associated with neurological decline in these patients as there was a significant indirect correlation of SARA scores and a trend towards significance of ICARS scores with height-for-age z-scores.

This study has some limitations. First, ATM gene variants were not genotyped in the patients with AT evaluated. Second, hepatic biopsies and additional nutritional assessments were not performed. Third, serial brain imaging studies were not conducted.

In conclusion, our study demonstrates a relevant correlation between severity of ataxia and disease progression with metabolic changes such as liver function impairment and insulin resistance in patients with AT. Therefore, with disease progression patients with AT may present with liver dysfunction and insulin resistance, and these findings reinforce the importance to monitoring metabolic changes and evaluate nutritional status in these patients. 
Table 1

Characteristics of patients with AT

\begin{tabular}{|c|c|c|}
\hline \multicolumn{2}{|l|}{ Variables } & \multirow{2}{*}{$\begin{array}{l}\mathbf{N}(\%) \\
10(40.0 \%)\end{array}$} \\
\hline Age (years) & $5-12$ & \\
\hline$(n=25)$ & $13-31$ & $15(60.0 \%)$ \\
\hline Nutritional status & Underweight & $8(32.0 \%)$ \\
\hline \multirow[t]{2}{*}{$(n=25)$} & Normal weight & $16(64.0 \%)$ \\
\hline & Overweight & $1(4.0 \%)$ \\
\hline Body fat mass & Low & $4(16.6 \%)$ \\
\hline \multirow[t]{2}{*}{$(n=24)$} & Normal & $13(54.1 \%)$ \\
\hline & High & $7(29.1 \%)$ \\
\hline MUAC & Low & $13(54.1 \%)$ \\
\hline$(n=24)$ & Normal & $8(44.4 \%)$ \\
\hline Sexual maturation staging & Prepubertal & 7 (28.0\%) \\
\hline \multirow[t]{2}{*}{$(n=25)$} & Pubertal & $11(44.0 \%)$ \\
\hline & Late pubertal & $7(28.0 \%)$ \\
\hline Symptom at disease onset & Ataxic gait & $15(60.0 \%)$ \\
\hline \multirow[t]{2}{*}{$(n=25)$} & Hypotonus & $7(28.0 \%)$ \\
\hline & Ocular telangiectasia & $3(12.0 \%)$ \\
\hline Gait & Walking without aid & $7(28.0 \%)$ \\
\hline \multirow[t]{2}{*}{$(n=25)$} & Walking with aid & $13(52.0 \%)$ \\
\hline & Inability to walk & $5(20.0 \%)$ \\
\hline ICARS scores & Mild ataxia & $3(12,0 \%)$ \\
\hline \multirow[t]{2}{*}{$(n=25)$} & Moderate ataxia & $13(52 \%)$ \\
\hline & Severe ataxia & $9(36 \%)$ \\
\hline SARA scores & Mild ataxia & $7(28.0 \%)$ \\
\hline \multirow[t]{2}{*}{$(n=25)$} & Moderate ataxia & $9(36.0 \%)$ \\
\hline & Severe ataxia & $9(36.0 \%)$ \\
\hline $\begin{array}{l}\text { Abbreviations: MUAC: mid-u } \\
\text { Rating Scale; SARA: Scale fc } \\
\text { percent. }\end{array}$ & $\begin{array}{l}\text { erence; ICARS; The Inte } \\
t \text { and Rating of Ataxia; }\end{array}$ & $\begin{array}{l}\text { erative Ataxi } \\
\text { value and }\end{array}$ \\
\hline
\end{tabular}


Table 2

Comparison of biochemical markers in patients with AT by age groups

\begin{tabular}{|lllll|}
\hline Variables & & $\begin{array}{l}\text { Age group 1 } \\
(\leq 12 \text { years }) \\
(\mathbf{n}=10)\end{array}$ & $\begin{array}{l}\text { Age group 2 } \\
(>12 \text { years }) \\
(\mathbf{n}=15)\end{array}$ & p-value ${ }^{\mathrm{a}, \mathrm{b}}$ \\
\hline AST & $\mathrm{U} / \mathrm{L}$ & $29.9(16.6-74.3)^{\mathrm{c}}$ & $37.7(16.6-82.3)$ & $0.360^{\mathrm{a}}$ \\
\hline ALT & $\mathrm{U} / \mathrm{L}$ & $18.4(11.4-45.0)$ & $31.4(16.3-144.5)$ & $\mathbf{0 . 0 1 7 ^ { \mathrm { a } }}$ \\
\hline GGT & $\mathrm{U} / \mathrm{L}$ & $17.5(7.0-97.0)$ & $37.0(21.0-612.0)$ & $<0.001^{\mathrm{a}}$ \\
\hline Fasting glucose & $\mathrm{mg} / \mathrm{dL}$ & $87.1( \pm 8.4)^{\mathrm{d}}$ & $87.4( \pm 12.1)$ & $0.950^{\mathrm{b}}$ \\
\hline Fasting insulin & $\mathrm{MIU} / \mathrm{mL}$ & $5.9(0.4-22.0)$ & $7.3(3.3-80.1)$ & $0.102^{\mathrm{a}}$ \\
\hline AFP & $\mathrm{IU} / \mathrm{mL}$ & $165.1( \pm 89.4)$ & $345.8( \pm 171.4)$ & $0.006^{\mathrm{b}}$ \\
\hline HOMA-IR index & & $1.15(0.07-4.44)$ & $1.75(0.51-20.94)$ & $0.102^{\mathrm{a}}$ \\
\hline
\end{tabular}

Abbreviations: AST: aspartate aminotransferase; ALT: alanine aminotransferase; AFP: alphafetoprotein; HOMA-IR: Homeostasis Model Assessment for Insulin Resistance.

${ }^{a}$ Level of significance for Mann-Whitney U-test

${ }^{b}$ Level of significance for independent Student's t-test

${ }^{\mathrm{c}}$ Median (minimum-maximum)

d Mean (standard deviation)

\section{Abbreviations}

AFP - Alpha-fetoprotein

ALT - Alanine aminotransferase

AST - Aspartate aminotransferase

AT - Ataxia-telangiectasia

ATM - Ataxia telangiectasia mutated

$\mathrm{BMI}$ - Body mass index

CNS - Central nervous system 
GGT - Gamma glutamyl transferase

ESID - European Society for Immunodeficiencies

HOMA-IR - Homeostasis Model Assessment for Insulin Resistance

ICARS - International Cooperative Ataxia Rating Scale

KAS - Klockgether ataxia score

SARA - Assessment and Rating of Ataxia

ZE/I - Height-for-age z-scores

ZIMC/I - Body mass index-for-age z-scores

\section{Declarations}

\section{Ethics approval and consent to participate}

The study was approved by the Ethics Committee in Research of the Universidade Federal de São Paulo (UNIFESP), identification number 0081/2018.

\section{Consent for publication}

Patients and parents gave consent to be included in the study through consent form.

\section{Availability of data and material}

All data generated or analysed during this study are included in this published article.

\section{Competing interests}

The authors declare that they have no competing interests.

\section{Funding}

Nothing to disclose.

\section{Authors' contributions}

TLNB: Acquisition of data; drafting of the manuscript; statistical analysis and interpretation of data of the manuscript.

IRR: Acquisition of data and critical revision for important intellectual content.

KKT: Acquisition of neurological data. 
FAM: Acquisition of neurological data.

JLP: Study supervision and critical revision for important intellectual content.

OGPB: Study supervision and critical revision for important intellectual content.

FLAF: Carried out the biochemical analysis.

ACF: Carried out the biochemical analysis.

CSA: Study supervision and critical revision for important intellectual content.

ROSS: Concept and design development; drafting of the manuscript; study supervision and critical revision for important intellectual content.

All authors read and approved the final manuscript.

\section{References}

1. Milne RL. Variants in the ATM gene and breast cancer susceptibility. Genome Med. 2009;1:12.

2. Swift M. Genetics and epidemiology of ataxia telangiectasia. Kroc Found Ser. 1985;19:133-146.

3. Lavin MF, Lederman HM. Chromosomal breakage syndromes associated with immunodeficiency. In: Stiehm ER, Ochs HD, Winkelstein JA, editors. Immunologic disorders in infants \& children. 5th edn. Philadelphia:Elsevier/Saunders; 2004. p. 580-587.

4. Stray-Pedersen A, Jónsson T, Heiberg A, Lindman CR, Widing E, Aberge IS, et al. The impact of an early truncating founder ATM mutation on immunoglobulins, specific antibodies and lymphocyte populations in ataxia-telangiectasia patients and their parents. Clin Exp Immunol. 2004;137:179186.

5. Gatti RA, Becker-Catania S, Chun HH, Sun X, Mitui M, Lai CH, et al. The pathogenesis of ataxiatelangectasia. Learning from a Rosetta Stone. Clin Rev Allergy Immunol. 2001;20:87-108.

6. da Silva R, dos Santos-Valente EC, Burim Scomparini F, Saccardo Sarni RO, Costa- Carvalho BT. The relationship between nutritional status, vitamin $A$ and zinc levels and oxidative stress in patients with ataxia-telangiectasia. Allergol Immunopathol (Madr). 2014; 42:329-335.

7. Ambrose M, Gatti RA. Pathogenesis of ataxia-telangiectasia: the next generation of ATM functions. Blood. 2013;121:4036-4045.

8. Lederman HM, Crawford TO. Visão geral da ataxia telangiectasia. In: St. Jude Children's Research Hospital - Memphis, Universidade Federal de São Paulo - UNIFESP, Brazilian Group for Immunodeficiencies - BRAGID editors. Ataxia Telangiectasia: livro para famílias e portadores. São Paulo:Editora Brasileira; 2006. p. 9-10.

9. McKinnon PJ. ATM and ataxia telangiectasia. EMBO Rep. 2004;5:772-776. 
10. Waldman TA, Mclntire KR. Serum alpha-fetoprotein levels in patients with ataxia-telangiectasia. Lancet. 1972;2:1112-1115.

11. Paulino TL, Rafael MN, Hix S, Shigueoka DC, Ajzen SA, Kochi C, et al. Is age a risk factor for liver disease and metabolic alterations in ataxia Telangiectasia patients? Orphanet $\mathrm{J}$ Rare Dis. 2017;12:136. 12. Andrade IG, Costa-Carvalho BT, da Silva R, Hix S, Kochi C, Suano-Souza FI, et al. Risk of Atherosclerosis in Patients with Ataxia Telangiectasia. Ann Nutr Metab. 2015;66:196-201.

12. Krauthammer A, Lahad A, Sarouk Y, Somech R, Nissenkorn A, Modan-Moses D, et al. Long-term nutritional and gastrointestinal aspects in patients with ataxia telangiectasia. Nutrition. 2018;46:4852.

13. Stewart E, Prayle AP, Tooke A, Pasalodos S, Suri M, Bush A, et al. Growth and nutrition in children with ataxia telangiectasia. Archives of Disease in Childhood. 2016;101:1137-1141.

14. Ross LJ, Capra S, Baguley B, Sinclair K, Munro K, Lewindon P, et al. Nutritional status of patients with ataxia-telangiectasia: A case for early and ongoing nutrition support and intervention. J Paediatr Child Health. 2015;51:802-807.

15. Nissenkorn A, Levy-Shraga Y, Banet-Levi Y, Lahad A, Sarouk I, Modan-Moses D. Endocrine abnormalities in ataxia telangiectasia: findings from a national cohort. Pediatr Res. 2016;79:889894.

16. Pommerening $\mathrm{H}$, van Dullemen $\mathrm{S}$, Kieslich M, Schubert R, Zielen S, Voss S. Body composition, muscle strength and hormonal status in patients with ataxia telangiectasia: a cohort study. Orphanet J Rare Dis. 2015;10:155. 18. Schubert R, Reichenbach J, Zielen S. Growth factor deficiency in patients with ataxia telangiectasia. Clin Exp Immunol. 2005;140:517-519.

17. Conley ME, Notarangelo LD, Etzioni A. Diagnostic criteria for primary immunodeficiencies. Representing PAGID (Pan-American Group for Immunodefiency) and ESID (European Society for Immunodeficiencies). Clin Immunol. 1999;93:190-197.

18. World Health Organization. Physical status: the use and interpretation of anthropometry: report of a WHO Expert Committee. World Health Organ Tech Rep Ser. 1995;854:1-452.

19. Frisancho AR. Anthropometric standards for the assessment of growth and nutritional status. Ann Arbor:The University of Michigan Press; 1990. p. 189.

20. de Onis M, Onyango AW, Borghi E, Siyam A, Nishida C, Siekmann J. Development of a WHO growth reference for school-aged children and adolescents. Bull World Health Organ. 2007;85:660-667.

21. Lohman TG. Advances in body composition assessment: current issues in exercises science. Illinois:Human Kinetic Publisher; 1992. p. 335.

22. Slaughter MH, Lohman TG, Boileau RA, Horswill CA, Stillman RJ, Van Loan MD, et al. Skinfold equations for estimation of body fatness in children and youth. Hum Biol. 1988; 60:709-723.

23. Deurenberg P, Pieters JJ, Hautuast JG. The assessment of the body fat percentage by skinfold thickness measurement in childhood e young adolescent. Br J Nutr. 1990;63:293-303.

24. Blackburn GL, Thornton PA. Nutritional assessment of the hospitalized patients. Med Clin North Am. 1979;63:11103-1115. 
25. Marshall WA, Tanner JM. Variations in pattern of pubertal changes in girls and boys. Arch Dis Child. 1969;44:291-303.

26. Maggi FA, Braga-Neto P, Chien HF, Gama MTD, Rezende Filho FM, Saraiva-Pereira ML, et al. Crosscultural adaptation and validation of the International Cooperative Ataxia Rating Scale (ICARS) to Brazilian Portuguese. Arq Neuropsiquiatr. 2018;76:674-684.

27. Braga-Neto P, Godeiro-Junior C, Dutra LA, Pedroso JL, Barsottini OG. Translation and validation into Brazilian version of the Scale of the Assessment and Rating of Ataxia (SARA). Arq Neuropsiquiatr. 2010;68:228-230.

28. Schon K, van Os NJH, Oscroft N, Baxendale H, Scoffings D, Ray J, et al. Genotype, extrapyramidal features, and severity of variant ataxia-telangiectasia. Ann Neurol. 2019; 85:170-180.

29. Schalch DS, McFarlin DE, Barlow MH. An unusual form of diabetes mellitus in ataxia telangiectasia. N Engl J Med. 1970;282:1396-1402.

30. Connelly PJ, Smith N, Chadwick R, Exley AR, Shneerson JM, Pearson ER. Recessive mutations in the cancer gene Ataxia Telangiectasia Mutated (ATM), at a locus previously associated with metformin response, cause dysglycaemia and insulin resistance. Diabet Med. 2016;33:371-375.

31. Arnold SE, Arvanitakis Z, Macauley-Rambach SL, Koenig AM, Wang HY, Ahima RS, et al. Brain insulin resistance in type 2 diabetes and Alzheimer disease: concepts and conundrums. Nat Rev Neurol. 2018;14:168-181.

32. Shin HW, Park HK. Recent Updates on Acquired Hepatocerebral Degeneration. Tremor Other Hyperkinet Mov (N Y). 2017;7:463.

33. Donath H, Woelke S, Theis M, Heß U, Knop V, Herrmann E, et al. Progressive Liver Disease in Patients with Ataxia Telangiectasia. Front Pediatr. 2019;7:458.

34. Weiss B, Krauthammer A, Soudack M, Lahad A, Sarouk I, Somech R, et al. Liver disease in pediatric patients with Ataxia Telangiectasia. J Pediat Gastroenterol Nutri. 2016;62:550-555.

\section{Figures}
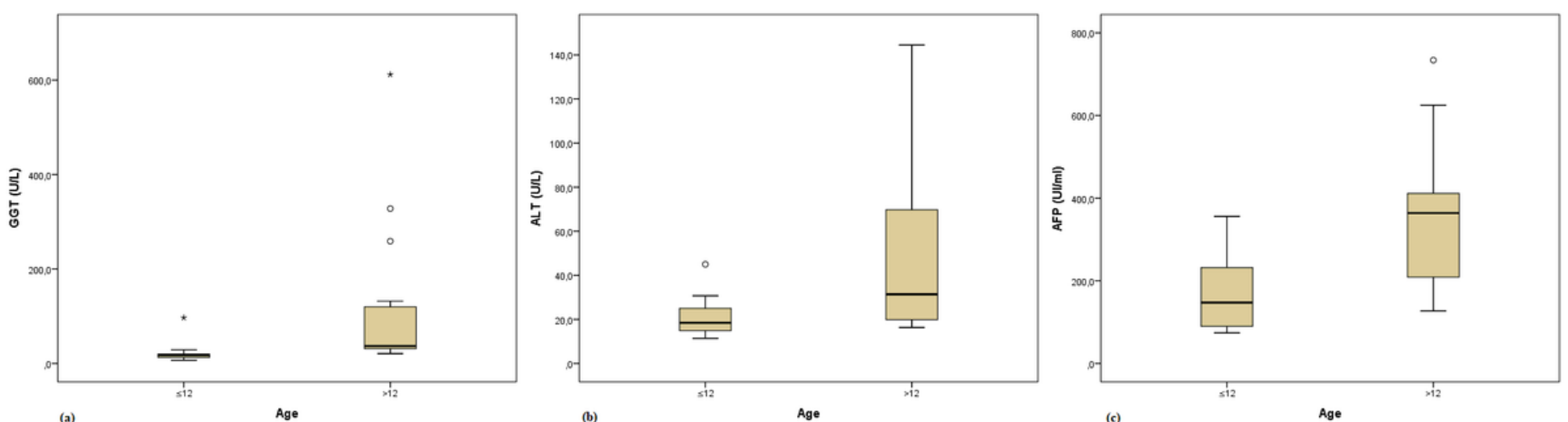

\section{Figure 1}


Boxplot of GGT (a); boxplot of ALT (b); and boxplot of AFP (c) for the age groups $\leq 12$ years $(n=10)$ and $>12$ years $(n=15)$

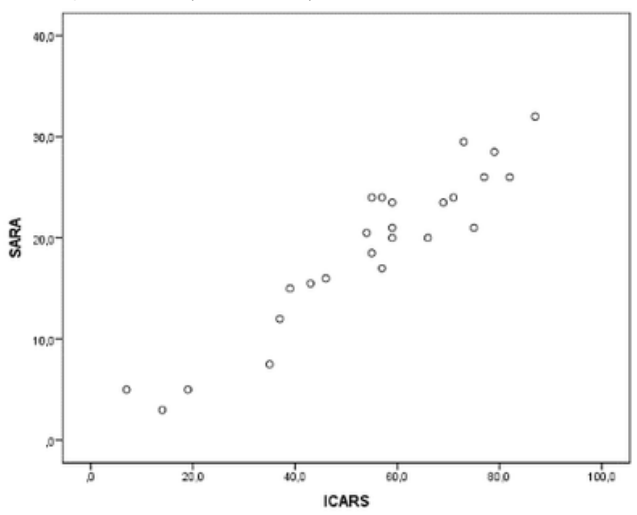

(a)

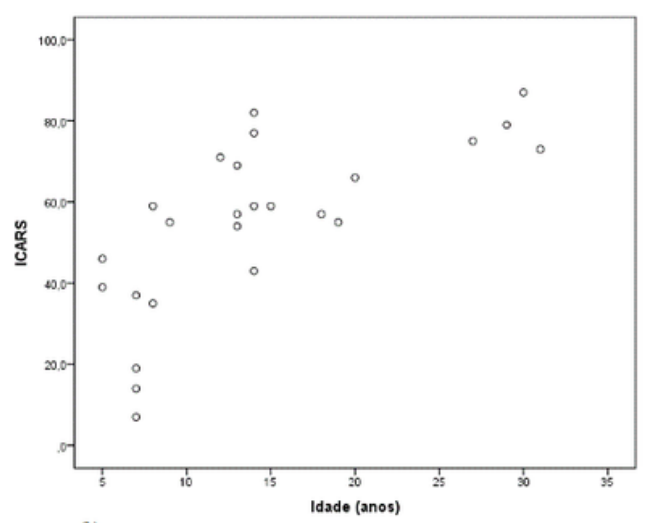

(b)

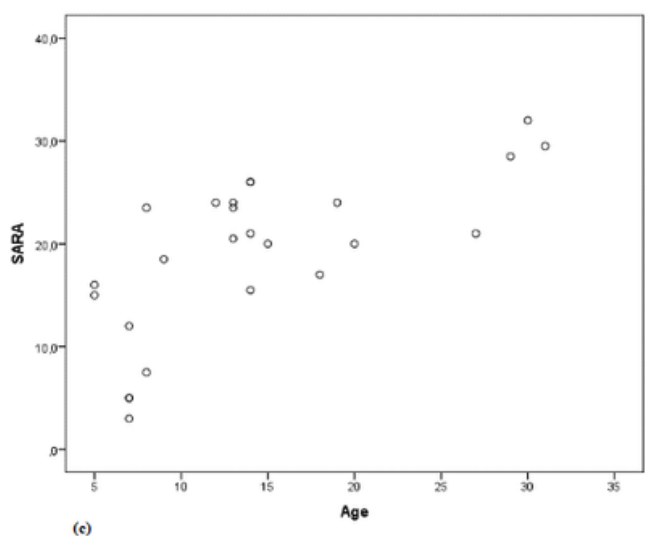

(c)

Figure 2

(a) Scatterplot of SARA and ICARS scores; (b) Scatterplot of ICARS scores versus age; and (c) Scatterplot of SARA scores versus age (c) 